\title{
Article
}

\section{The Application of Food-Grade Chemical Treatment and Its Effect on the Mechanical Performance Characteristics of Ham Nets}

\author{
Md. Al-Amin ${ }^{1}$, , Charles Freeman ${ }^{1, *}$, Wes Schilling ${ }^{2}$, Catherine Black ${ }^{1}$, Yan Li Campbell ${ }^{2}$, Wenjie Shao ${ }^{2}$, \\ Santanu Kundu ${ }^{3}$ and Anandavalli Varadajan ${ }^{3}$
}

check for

updates

Citation: Al-Amin, M.; Freeman, C.; Schilling, W.; Black, C.; Campbell, Y.L.; Shao, W.; Kundu, S.; Varadajan, A. The Application of Food-Grade Chemical Treatment and Its Effect on the Mechanical Performance Characteristics of Ham Nets. Eng 2021, 2, 468-479. https://doi.org/ 10.3390/eng2040029

Academic Editor: Antonio Gil Bravo

Received: 8 September 2021

Accepted: 15 October 2021

Published: 22 October 2021

Publisher's Note: MDPI stays neutral with regard to jurisdictional claims in published maps and institutional affiliations.

Copyright: (C) 2021 by the authors. Licensee MDPI, Basel, Switzerland. This article is an open access article distributed under the terms and conditions of the Creative Commons Attribution (CC BY) license (https:/ / creativecommons.org/licenses/by/ $4.0 /)$.
1 Department of Fashion Design and Merchandising, Mississippi State University, Starkville, MI 39762, USA; alamintex20@yahoo.com (M.A.-A.); cblack@humansci.msstate.edu (C.B.)

2 Department of Food Science, Nutrition, and Health Promotion, Mississippi State University, Starkville, MI 39762, USA; schilling@foodscience.msstate.edu (W.S.); ycampbell@foodscience.msstate.edu (Y.L.C.); ws525@msstate.edu (W.S.)

3 Department of Chemical Engineering, Mississippi State University, Starkville, MI 39762, USA; santanukundu@che.msstate.edu (S.K.); av234@msstate.edu (A.V.)

* Correspondence: cf617@msstate.edu

\begin{abstract}
This study involves the use of food-grade chemicals in the integrated pest management of dry-cured ham through the use of $100 \%$ polyester weft knitted mesh nets, an idea that was derived from a previously published study in the literature. Tubular mesh nets that are used to contain dry-ageing hams, commonly referred to as ham nets, were treated with a patent-pending food-grade chemical solution ( $40 \%$ Propylene Glycol $+1 \%$ Propylene Glycol Alginate $+1 \%$ Carrageenan) to control ham mites. Both treated and untreated ham nets were compared for mechanical performance characteristics based on the following standards: abrasion resistance (ASTM D4966), elastic recovery (BS EN 14704-1:2005), breaking strength (ASTM D5034-09), and bursting strength (ASTM D3786). The results indicate that the chemical treatment had minimal to no impact on the mechanical performance characteristics of ham nets. The obtained SEM images also showed no negative effect on the fiber morphology due to the applied chemical solution. The findings support the use of treated ham nets to increase the end-use functionality and provide ham producers an option for integrated pest management without compromising mechanical performance needs.
\end{abstract}

Keywords: dry-cured ham; food-grade chemical; coating; mechanical performance characteristics; chemical treatment; ham nets; pest management; mechanical test; mesh fabric

\section{Introduction}

Dry-cured ham aging involves the use of textiles to hang the cured meat for 3-24 months to develop the desired flavor. During the aging process, one type of mite, Tyrophagus putrescentiae, commonly referred to as a ham mite, may grow on the ham's surface [1]. A vital component of a pest management program in the ham industry uses the fumigant Methyl Bromide (MB). Since 1930, MB, as a fumigant, controlled ham mites during aging, but production is no longer permitted globally [2]. However, the dry-cured ham industry exercises an exemption to use the existing stock, and this has significantly increased the $\mathrm{MB}$ price. Therefore, it is critical to find a safe, effective, and cheap alternative to MB before depleting the existing stock [3].

A safe and cheap MB alternative is not only functionally significant but also impacts economic and dietary significance. Dry-cured ham is one of the most popular forms of ham among the market's available types [4]. In 2019, the United States consumed approximately 3.3 million tons of hams, which estimates approximately $\$ 2.9$ billion and predicted to be $\$ 3.1$ billion in 2020 with a growth rate of 2.6\% [5]. In Europe, Italy, Spain, and France produce 325,000 tons of dry-cured hams each year [6]. In terms of nutritional 
and dietary advantages, dry-cured ham is useful for cardiovascular disorders, high blood pressure, various types of cancer, diabetes, and obesity [7]. The United States Department of Agriculture (USDA) does not allow the sale of homemade country ham to the public due to mites, mold, and fungi on the surface [8]. Therefore, all the dry-cured ham sold in the U.S. is from a commercial or industrial processor. Any delay for an MB alternative before consuming the current MB stock will jeopardize the commercial dry-cured ham industry in the United States.

The application of chemical layers directly on the textile surface adds functionality and value, which enhances the tactile qualities, and aesthetic appearances are considered the most feasible technology to alter textiles' surface performance [9]. Some common examples of surface treatments include water repellency, flame retardant, and lamination [10]. The treatment materials directly influence the performance characteristics of the end product [11]. Apart from the functional advantages, the surface treatments have some disadvantages, such as surface defect and messiness, superficial saturation, large energy consumption, and short-lived adhesion [12]. In terms of polymer deposition on the surface, the polymer and fabric must endure distortion and recover from daily wear, such as twisting and stretching. The polymer coating must retain the surface's structure and shape when exposed to the environment [13]. Various functional additives, such as organic compounds, inorganic particles, and polymers, are used on synthetic textiles to strengthen the mechanical performance characteristics to apply those in the food industry [14]. These treatments improve the textiles' mechanical performance, providing, for example, high mechanical strength, wear, and abrasion resistance, and thus, offer possible methods for varying surface performance. Moreover, the surface treatment also affects the textiles' mechanical performance characteristics [15].

Niekraszewicz et al. (2005) [16] applied an anti-mite modified polypropylene (PP) fiber in the nonwoven textiles to fabricate bedding inserts. The results indicated that the addition of anti-mite agents $(0.25 \%$ to $2.5 \% \mathrm{wt})$ in the PP fiber did not affect the final nonwoven's physical-mechanical properties. The results indicate positive effects on mild allergy conditions and the controlling of the population of dust mites. However, the results of the study report limitations to its efficacy against other species of mites. Rahel et al. (2013) [17] carried out a chitosan surface coating with metal $\left(\mathrm{Cu}^{2+}, \mathrm{Ag}^{+}, \mathrm{Zn}^{2+}\right)$ ions on plasma-treated nonwoven textiles. The results indicated that the chitosan with Ag+ metal ion coating on the ham netting was significantly effective against the ham mites. However, the researchers do not recommend applying chitosan $/ \mathrm{Ag}^{+}$on the food surface due to its high toxicity. The coating effects on the nonwoven textiles' mechanical properties were outside the 2013 study's scope. Abbar et al. (2016) [18] used a coating of propylene glycol, lard, ethoxyquin, or butylated hydroxytoluene on the ham surface. They also used another coating of food-grade ingredient solution that includes PG, PGA, CG on the ham by dipping the ham cubes into the coating solution. The results indicated that the food-grade ingredients were effective in inhibiting the reproduction of ham mites.

Zhang et al. (2017) [3] applied a coating of food-grade ingredients on ham nets by means of dip coating at the laboratory settings. The food-grade ingredient coating includes Xanthan Gum (XG), Propylene Glycol (PG), Propylene Glycol Alginate (PGA), and Carrageenan (CG). Dip coatings effectively inhibited the growth and reproduction of ham mites without affecting the ham's sensory qualities. As in previous studies, the researchers did not examine the coating solutions' effect on the treated ham nets' mechanical performance characteristics. Campbell et al. $(2017,2018)[1,2]$ used polyester/cotton and cotton nets coated with PG, PGA, and CG on the laboratory scale. The results indicated that the coated nets controlled the infestation of ham mites more effectively than the untreated nets and directly treated ham. However, this study did not conduct a mechanical performance evaluation of the treated versus untreated nets. They also reported that all previous works were not economically feasible in commercial settings. 


\subsection{Research Gap}

Prior research on MB alternatives to dry-cured ham nets focuses primarily on the effectiveness of chemical alternatives to control ham mites. Research remains limited in terms of the effect of the applied chemicals on the mechanical performance characteristics of treated ham nets. In the dry-cured ham aging process, a whole green ham weighs around $8 \mathrm{~kg}-10 \mathrm{~kg}(17.8 \mathrm{lb}-22.22 \mathrm{lb})$, which exerts pressure on the multi-direction of the nets during aging [2]. The hanging mass on nets imparts forces simultaneously in all directions [19]. The breaking strength test measures the breaking force of the specimen lengthwise or widthwise, which does not conform to the exerted multi-directional pressure [20] of ham to the netting during aging. Dry-cured hams exert heavy stress on the nets for a long time. Therefore, maintaining the treated nets' mechanical performance characteristics compared to untreated nets throughout the aging period is necessary. Campbell et al. (2018) reported that $40 \%$ PG, $1 \%$ PGA, and 1\% CG coating solution, when applied on $100 \%$ polyester ham nets, could effectively slow down the ham mite growth. In a follow-up preliminary performance study, Al-Amin et al. (2020) indicated that the application of a coating solution does not affect the mechanical performance characteristics of various fiber ham nets. Abrasion resistance, breaking strength, and elastic recovery testing methods were used to assess the mechanical performance evaluation. However, limitations included failure to evaluate biaxial bursting strength performance, direct net construction comparisons, and exact fiber/yarn size comparisons.

Therefore, based on the preliminary study [21] the following limitations were identified.

No biaxial test, such as the bursting strength test, was performed, which is the most important mechanical test for ham nets.

All mesh nets were not of the same construction, in terms of, for example, weight in grams per square meter (GSM) and stich length, although the fiber contents were of $100 \%$ cotton, and thus, a true comparison could not be justified.

The sample size was not consistent across all the performed tests, such as ten for the tensile strength test and six for the abrasion-resistance test, which may have brought inconsistency in the results.

Visual assessment of abrasion resistance with the gray scale for color change did not always reflect the expected outcome for mechanical performance characteristics. Gray scale, for color change, was predominantly used for the colorfastness test.

\subsection{Purpose of the Study}

Therefore, the purpose of this study is to make a true comparison of the effect of food-grade PG solution treatment on the mechanical performance characteristics (abrasion resistance, elastic recovery, breaking strength, and bursting strength) between treated and untreated $100 \%$ polyester ham nets based on the identified research gaps and limitations of the preliminary study of Al-Amin et al. (2020).

\subsection{Hypotheses}

Based on the previous studies, and the purposes of those studies, the following hypotheses were formulated.

$\mathbf{H a}_{\mathbf{0}}$. The results will not validate the preliminary findings of no significant differences in the abrasion resistance between treated and untreated ham nets.

$\mathbf{H a}_{\mathbf{a} .}$. The results will validate the preliminary findings of no significant differences in the abrasion resistance between treated and untreated ham nets.

$\mathbf{H b}_{\mathbf{0}}$. The results will not validate the preliminary findings of no significant differences in the elastic recovery between treated and untreated ham nets.

$\mathbf{H b}_{\mathbf{a}}$. The results will validate the preliminary findings of no significant differences in the elastic recovery between treated and untreated ham nets. 
$\mathbf{H c}_{0}$. The results will not validate the preliminary findings of no significant differences in the breaking strength between treated and untreated ham nets.

$\mathbf{H c}_{\mathbf{a} .}$. The results will validate the preliminary findings of no significant differences in the breaking strength between treated and untreated ham nets.

$\mathbf{H d}_{\mathbf{0}}$. There will be no significant differences in the bursting strength between treated and untreated ham nets.

$\mathbf{H d}_{\mathbf{a} .}$. There will be a significant difference in the bursting strength between treated and untreated ham nets.

\section{Materials and Methods}

Based on the previous studies and the hypotheses developed, a quantitative research methodology was used to evaluate the comparison of mechanical performance characteristics between a treated knit mesh net and an untreated knit mesh net of the same lot. Earlier research indicated that the treatment of a ham net with a Propylene Glycol (PG), Propylene Glycol Alginate (PGA), and Carrageenan (CG) solution improved the end-use functionality of the ham nets [1]. However, this research (Campbell et al., 2018) did not examine the effect of the treatment on the mechanical performance characteristics of that net. Initial research validates the application of abrasion resistance (ASTM D4966), breaking strength (ASTM D5034-09), elastic recovery (BS EN 14704-1:2005), and bursting strength (ASTM D3786) test methods to evaluate mechanical performance characteristics of treated and untreated ham nets. Apart from the mechanical performance characteristic testing procedures, both treated and untreated ham nets were assessed by visual morphology analysis. Data obtained from the mechanical performance characteristic tests were analyzed by independent sample $t$-test using the Statistical Package for Social Sciences (IBM SPSS, Version 26.0, IBM, New York, NY, USA).

\subsection{Samples}

The untreated circular knit ham nets (Figure 1a) with the technical specifications of (1) $100 \%$ polyester, (2) weight of $140 \mathrm{~g}$ per square meter (GSM), (3) a stitch length of $63.4 \mathrm{~cm}$ per 200 needles, (4) a wale per inch (WPI) of $24.8\left(3.9 / \mathrm{cm}^{2}\right)$, (5) a course per inch (CPI) of $39.4\left(6.1 / \mathrm{cm}^{2}\right)$, and (6) a diameter of $19.8 \mathrm{~cm}$ were provided by Dickson Industries, Inc., Des Moines, IA, USA. Half of the received untreated sample was treated following the treatment procedures outlined by Campbell et al. (2018). Ten specimens from each of the samples were selected for each of the tests in accordance with the recommendation of earlier studies and the respective ASTM and BS test methods.

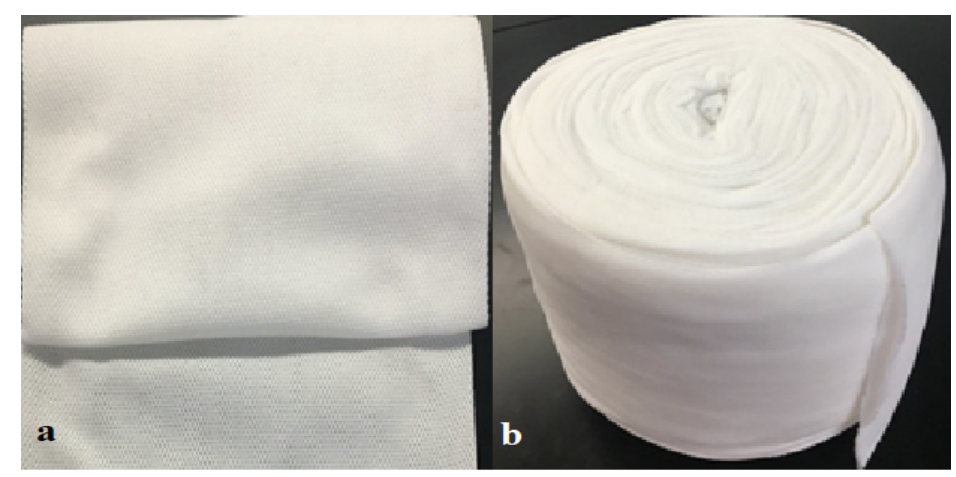

Figure 1. Untreated (a) and treated (b) ham net sample.

\subsection{Chemical Solution}

According to Campbell et al. (2018), a food-grade chemical solution of $40 \%$ PG $+1 \%$ PGA $+1 \%$ CG was prepared for the surface treatment. Here, PG is the main ingredient to 
control the growth of the ham mite. PGA and CG are the binders to keep the PG on the net and prevent evaporation of the PG. The PG was acquired from Hawkins, Inc. (Roseville, MN, USA) with the lot number 384,781; the PGA and CG were provided by TIC Gums, White Marsh, MD, USA. At first, one liter of $400 \mathrm{~g}$ PG solution was prepared. Then, $10 \mathrm{~g}$ of carrageenan (CG) and $10 \mathrm{~g}$ of propylene glycol alginate (PGA) were slowly mixed into the PG solution. After that, all of the solution, containing $420 \mathrm{~g}$ of chemicals, was taken into a pot of three-liter volume where $580 \mathrm{~g}$ of warm $\left(35^{\circ} \mathrm{C}-50{ }^{\circ} \mathrm{C}\right)$ water was added slowly by vigorous stirring. The solution was heated up with continuous stirring until the temperature reached at $85^{\circ} \mathrm{C}$. Finally, the solution was transferred to a netting machine (Midwest Metal Craft \& Equipment Company, Winsor, MO, USA) to immerse the nets into the solution. The soaked nets were squeezed when passing through a padding roller. The treated nets (Figure 1b) were vacuum packed and kept for conditioning.

\subsection{Conditioning}

Before the mechanical performance characteristic testing, samples were preconditioned according to ASTM D1776/D1776M Standard Practice for Conditioning and Testing Textiles. Both treated and untreated samples were kept in a conditioned laboratory at the temperature of $20 \pm 2{ }^{\circ} \mathrm{C}\left(68 \pm 4{ }^{\circ} \mathrm{F}\right)$ with a relative humidity $(\mathrm{RH})$ of $65 \pm 2 \%$. The treated sample was packed with a $(50.8 \mathrm{~cm} \times 71.12 \mathrm{~cm})$ vacuum bag $(3 \mathrm{~mL}$ standard barrier, nylon/PE clarity pouches, Kansas City, MO, USA) with a dual chamber vacuum packaging machine (Model 2100, Koch equipment LLC, Kansas City, MO, USA) as it contained volatile chemical solution, whereas the untreated samples remained flat on a table surface at $20^{\circ} \mathrm{C}$. However, both the treated and untreated samples received sufficient conditioning before the test, as per the aforementioned ASTM standard.

\subsection{Mechanical Performance Test}

The recommended methodologies from the prior studies were followed to evaluate the mechanical performance characteristics, such as abrasion resistance, elastic recovery, breaking strength, and bursting strength. The apparatuses, specimen selection, procedures, evaluation, and data reporting were followed in accordance with the international standard guidelines set by ASTM International [22-24] and the British Standards Institute.

\subsubsection{Abrasion Resistance}

A six-head Nu-Martindale abrasion and pilling tester (James Heal, UK) was used to test the abrasion resistance following the ASTM standard method D4966-Standard Test Method for Abrasion Resistance of Textile Fabrics (Martindale Abrasion Tester Method) with 9 kilopascals $(\mathrm{kPa})$ of pressure on each head. The specimens were cut as circular areas with diameters of $38 \mathrm{~mm}$. ASTM recommends testing at least three specimens from each of the samples [25]. Moreover, Nautiyal and Vasugi (2018) [26] evaluated five specimens for their abrasion resistance test of single jersey cotton fabric samples. Hence, as a valid number, ten random specimens from both the treated and untreated samples were evaluated.

According to the ASTM standard D4966, the six-head Nu-Martindale Abrasion and Pilling Tester was calibrated. The circular specimens were cut using a press cutter and inserted on the head of the tester with the support of a circular polyurethane foam of equal area to the specimen in between the specimen and metal insert to keep the specimen flat and even throughout the abrasion cycle. The specimens were abraded until the first thread broke by showing a hole on the abraded surface. After 7000 cycles, the specimens were checked in a regular interval of 500 cycles. The number of cycles abraded to make a hole or break the first yarn was recorded.

\subsubsection{Elastic Recovery}

A Fabric Extensometer (James Heal, UK) was used to test the elastic recovery following the standard test procedures of BS EN 14704-1:2005. Wardiningsih et al. (2013) [27] evaluated five specimens from each of the samples, for each direction, in their elastic 
recovery test of compression garments, which validates that five or more specimens is a valid number for this mechanical test. However, to obtain more accurate results, ten random specimens from each of both the course and wale directions, from the treated and untreated nets, were evaluated according to the following procedures outlined in BS EN 14704-1:2005.

The specimen size was cut as $85 \mathrm{~mm} \times 75 \mathrm{~mm}$. Two reference points were marked on the specimens aligning perpendicular to the two jaws on the tester. The linear distance between the reference points $(\mathrm{P})$ was recorded. One jaw was fixed, and the other was movable. The minimum and initial distance between the jaws was constantly $75 \mathrm{~mm}(\mathrm{E})$. After inserting the specimen into the jaws of the extensometer, a $3 \mathrm{~kg}$ mount weight was hung to the movable jaws, with the support of a metal wire, to expedite the extension force to the specimen at the time of extending the movable jaw. The distance between the jaws after turning the wheel (L) five times was recorded. The specimen was taken off after at least ten seconds. The distance between the reference points (Q) was recorded. All the measurements were taken in $\mathrm{mm}$. The procedure was undertaken for both directions of the treated and untreated specimens. Calculations were made following the equation outlined in BS EN 14704-1:2005.

$$
\begin{gathered}
S=\frac{L-E}{E} \times 100 \% \\
C=\frac{Q-P}{P} \times 100 \% \\
D=100 \%-C \\
R=\frac{D}{S} \times 100 \%
\end{gathered}
$$

Note: $\mathrm{S}=$ elongation; $\mathrm{C}=$ unrecovered elongation; $\mathrm{D}=$ recovered elongation; $\mathrm{R}=$ elastic recovery; $\mathrm{L}=$ length after 5th cycle; $\mathrm{E}=$ initial length; $\mathrm{Q}=$ distance between reference marks after 5th cycle; $\mathrm{P}=$ initial distance between reference marks.

\subsubsection{Breaking Strength}

A Mark-10 ESM 1500 tensile strength tester was used to test the breaking strength following the ASTM D5034-09 Breaking Strength and Elongation of Textile Fabrics-Grab Test as the standard method for breaking strength, with a load cell of $226.8 \mathrm{~kg}$ and a gauge length of $6.35 \mathrm{~cm}$. Specimens were cut with their long dimensions parallel to both the course and wale directions, at a size of $7.62 \mathrm{~cm}$ by $5.08 \mathrm{~cm}$ ( 3 inches $\times 2$ inches), from both the treated and untreated samples. The ASTM recommends testing at least three specimens from each of the samples [23]. However, as a valid specimen number, ten random specimens, for each of the directions, from both treated and untreated samples were evaluated.

The cut specimen was placed lengthwise in the jaws of the tensile tester. The bottom jaw was fixed while the upper jaw was movable. Once the upper jaw started moving upward, the specimen also started extending. At a certain point, the applied load broke the specimen. The maximum load $(\mathrm{N})$ at the breaking point was recorded.

\subsubsection{Bursting Strength}

A Truburst ${ }^{4}$ (model-1440 Truburst $^{4}$, James Heal, UK) pneumatic bursting strength tester was used to test the bursting test following the ASTM D3786 Standard Test Method for Bursting Strength of Textile Fabrics-pneumatic bursting strength tester method. The tester has built-in calibrated test procedures based on the ASTM International and ISO standards. This test requires a maximum air pressure of $1000 \mathrm{kPa}\left(\mathrm{kN} / \mathrm{m}^{2}\right) / 145 \mathrm{psi} / 10 \mathrm{bar}$. The circular rubber diaphragm and the specimen had a diameter of $29.8 \mathrm{~cm}$, whereas the testing area was $7.3 \mathrm{~cm}^{2}$ (diameter $30.5 \mathrm{~mm}$ ). Nautiyal and Vasugi (2018) evaluated five specimens for the bursting strength test of single jersey cotton fabric using the ASTM D3786 method. Hence, as valid number, 10 random specimens were evaluated from both untreated and treated samples. 
The circular specimens were cut at an equal diameter of the rubber diaphragm. At first, the diaphragm was inserted at the center of the test area. The specimen was placed on the diaphragm and the dome was set on the test area. Then, the Truburst ${ }^{4}$ was run with an air pressure of $1000 \mathrm{kPa}$ according to the built-in ASTM standard calibrated method, and this continued until the sample burst with the required pneumatic pressure. The maximum bursting pressure $(\mathrm{kPa})$, distension $(\mathrm{mm})$, and time (s) to burst the specimen were recorded.

\subsubsection{Fiber Morphology Analysis}

Scanning Electron Microscope (SEM) images of treated and untreated ham nets were taken using a ZEISS EVO-50 H (Germany) scanning electron microscope to observe the fiber morphology and to investigate the in-depth effect of the chemical treatment on the fiber physiology. All the images were processed at different microscales $(20 \mu \mathrm{m}, 50 \mu \mathrm{m}$, $100 \mu \mathrm{m}$, and $200 \mu \mathrm{m}$ ) and at magnification levels ranging from $95 \times$ to $501 \times$.

\subsection{Statistical Analysis}

The Statistical Package for Social Sciences (SPSS) software (version 26.0, IBM, New York, NY, USA) was used to analyze the data to compare the mechanical performance characteristics between the treated and untreated samples. To investigate the mechanical performance characteristics, an independent samples $t$-test, at a $95 \%$ confidence interval, was conducted for each of the samples as follows: abrasion resistance, elastic recovery (course and wale direction), breaking strength (course and wale direction), and bursting strength. The independent sample $t$-test is used to compare the means between two sample groups, which is mostly convenient in cases in which there are equal specimen sizes from both sample groups. The equal specimen sizes neutralize possible errors due to unequal standard deviation (SD) [28]. For hypotheses testing, the independent sample $t$-test is applicable for even small sample sizes $(N \leq 5)$ [29]. Therefore, the independent sample $t$-test has been a valid statistical method for the testing of hypotheses when comparing mechanical performance characteristics between untreated and treated ham nets through the evaluation of an equal number of specimens from both groups of samples.

\section{Results and Discussion}

\subsection{Abrasion Resistance}

The average abrasion cycles for both the treated and untreated samples were more than 11,000 . Usually, $100 \%$ polyester knitted fabrics can withstand up to 10,000 abrasion cycles, given that the mechanical properties of the fabric vary with the type of fibers, yarns, fabric structure, and finish [30]. The results of the independent samples $t$-test were not found to be statistically significant, $t(18)=-0.93, p>.05$, resulting in the preliminary findings of no significant difference in abrasion resistance between treated samples $(\mathrm{M}=12,800$, $\mathrm{SD}=3146.43, \mathrm{df}=9)$ and untreated samples $(\mathrm{M}=11,750, \mathrm{SD}=1654.12, \mathrm{df}=9)$ not being validated. Hence, the null hypothesis was accepted (Table 1). In addition, the significant difference in abrasion resistance between treated and untreated ham nets stated in the preliminary study was not validated. Moreover, the result is consistent with the existing literature on the mechanical properties of $100 \%$ polyester fabric under Martindale Abrasion testing.

\subsection{Elastic Recovery}

The independent samples $t$-test was conducted in both the wale and course directions. The independent $t$-test for the wale direction showed a statistically significant difference between the elastic recovery of treated $(\mathrm{M}=5.64, \mathrm{SD}=.768, \mathrm{df}=9)$ and untreated $(\mathrm{M}=7.36$, $\mathrm{SD}=0.66, \mathrm{df}=9)$ samples; $t(18)=5.38, p<.05$. Therefore, the null hypothesis was rejected (Table 1). The results validate the preliminary study of significant effects of food-grade treatment on the elastic recovery of the ham nets. Therefore, the significant difference in elastic recovery in the wale direction between the treated and untreated ham nets stated in the preliminary study was validated. 
Table 1. Independent samples $t$-test of abrasion resistance, elastic recovery, breaking strength, and bursting strength test.

\begin{tabular}{|c|c|c|c|c|c|c|c|c|}
\hline Tests & Samples & DF $^{1}$ & $\mathbf{M}^{2}$ & $\mathrm{SD}^{3}$ & $\mathrm{SE}^{4}$ & $95 \% \mathrm{CI}^{5}$ & $t$ & $p$ \\
\hline \multirow{3}{*}{$\begin{array}{l}\text { Abrasion } \\
\text { Resistance }\end{array}$} & Treated & 9 & 12,800 & 3146.43 & 994.99 & $(10,45915,050)$ & & \\
\hline & Untreated & 9 & 11,750 & 1654.12 & 523.08 & $(10,566$ 12,933) & & \\
\hline & Eq. Var. diff ${ }^{6}$ & 18 & & 2852.39 & 1124.1 & $(-34671367)$ & -0.93 & .37 \\
\hline \multirow{3}{*}{$\begin{array}{c}\text { Elastic } \\
\text { Recovery } \\
\text { (Wale) }\end{array}$} & Treated & 9 & 5.64 & 0.768 & 0.24 & (5.09 6.19) & & \\
\hline & Untreated & 9 & 7.36 & 0.66 & 0.21 & (6.89 7.83) & & \\
\hline & Eq. Var. diff & 18 & & 0.77 & 0.32 & (1.05 2.40) & 5.38 & $<.05$ \\
\hline \multirow{3}{*}{$\begin{array}{c}\text { Elastic } \\
\text { Recovery } \\
\text { (Course) }\end{array}$} & Treated & 9 & 4.82 & 0.23 & 0.07 & $(4.664 .99)$ & & \\
\hline & Untreated & 9 & 5.06 & 0.41 & 0.13 & $(4.775 .35)$ & & \\
\hline & Eq. Var. diff & 18 & & 0.26 & 0.15 & $(-0.0750 .55)$ & 1.6 & .13 \\
\hline \multirow{3}{*}{$\begin{array}{c}\text { Breaking } \\
\text { Strength } \\
\text { (Wale) }\end{array}$} & Treated & 9 & 143.8 & 27.60 & 8.73 & (124 164) & & \\
\hline & Untreated & 9 & 99.5 & 19.95 & 6.31 & $(85$ 114) & & \\
\hline & Eq. Var. diff & 18 & & 28.87 & 10.77 & $(-68-22)$ & -4.11 & $<.05$ \\
\hline \multirow{3}{*}{$\begin{array}{l}\text { Breaking } \\
\text { Strength } \\
\text { (Course) }\end{array}$} & Treated & 9 & 114.50 & 13.14 & 4.16 & (105 124) & & \\
\hline & Untreated & 9 & 114.50 & 9.00 & 2.85 & (108 121) & & \\
\hline & Eq. Var. diff & 18 & & 15.12 & 5.03 & $(-10.58$ 10.58) & 00 & 1.00 \\
\hline \multirow{3}{*}{$\begin{array}{l}\text { Bursting } \\
\text { Strength }\end{array}$} & Treated & 9 & 120.64 & 3.19 & 1.01 & (118 123) & & \\
\hline & Untreated & 9 & 120.29 & 2.48 & .78 & (119 122) & & \\
\hline & Eq. Var. diff & 18 & & 1.85 & 1.27 & $(-3.02 .33)$ & -0.277 & .79 \\
\hline
\end{tabular}

${ }^{1}$ degree of freedom, ${ }^{2}$ mean, ${ }^{3}$ standard deviation, ${ }^{4}$ standard error, ${ }^{5}$ confidence interval, ${ }^{6}$ equal Variance difference.

The results obtained for the course direction did not show a statistically significant difference between the elastic recovery of treated $(\mathrm{M}=4.28, \mathrm{SD}=0.23, \mathrm{df}=9)$ and untreated $(\mathrm{M}=5.06, \mathrm{SD}=0.41, \mathrm{df}=9)$ samples; $t(18)=1.6, p>.05$. Therefore, the null hypothesis was accepted (Table 1). Naturally knitted mesh fabrics are elastic due to the structure of loops, which is why the effects of Poisson's Ratio (PR) and Young's Modulus (YM) are predominant in knit fabrics compared to woven fabrics [31]. However, graphical representation of elastic recovery in the wale direction (Figure 2) shows that untreated samples have better elastic recovery values than those of treated samples. The elastic recovery performances are less consistent after the treatment. On the other hand, in the course direction (Figure 3) the untreated samples do not change significantly in terms of their elastic recovery performance characteristics upon receiving food-grade chemical treatment. The values are almost consistent for both types of samples.

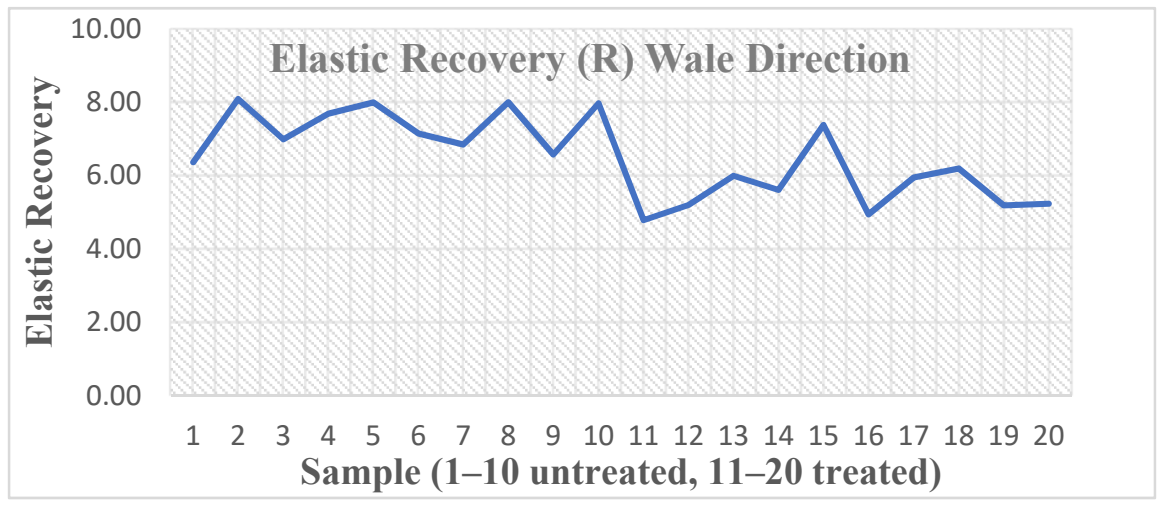

Figure 2. Elastic Recovery in wale direction. 


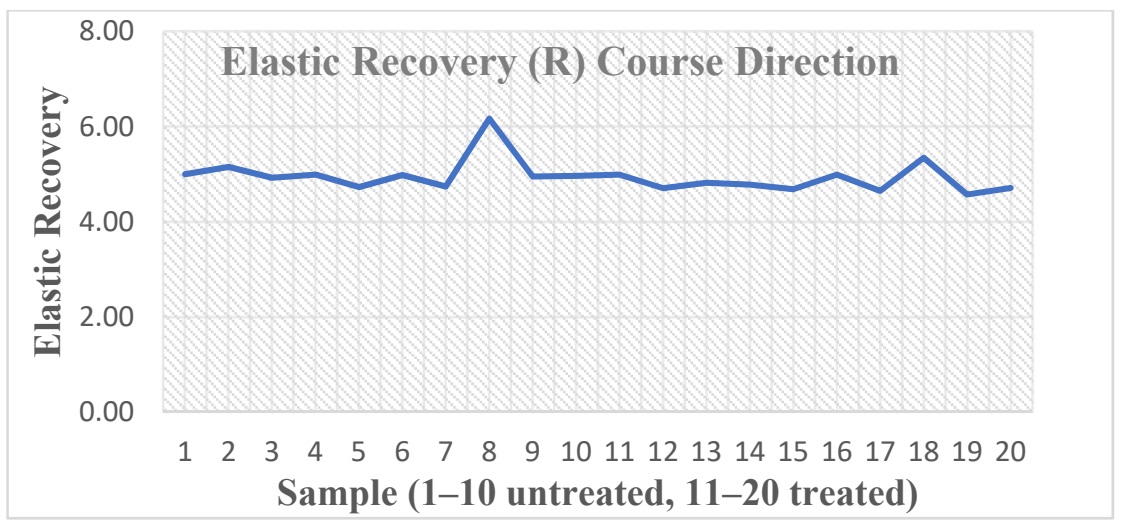

Figure 3. Elastic Recovery in course direction.

The results validate the preliminary study of the significant effects of food-grade treatment on the elastic recovery of the ham nets. Therefore, the significant difference in elastic recovery in the course direction between the treated and untreated ham nets stated in the preliminary study has also been validated. The results from the elastic recovery tests in both directions provide information indicating that the knitted mesh ham net is able to perform in its originally intended state.

\subsection{Breaking Strength}

The breaking strength test in the wale direction shows a statistically significant difference between the treated $(\mathrm{M}=143.80, \mathrm{SD}=27.60, \mathrm{df}=9)$ and untreated $(\mathrm{M}=99.50$, $\mathrm{SD}=19.95, \mathrm{df}=9)$ samples; $\mathrm{t}(18)=-4.11, p<.05$. Therefore, the null hypothesis was rejected (Table 1). The results validate the preliminary study of the significant effects of food-grade treatment on the breaking strength of the ham nets. Therefore, the significant difference in breaking strength in the wale direction between the treated and untreated ham nets stated in the preliminary study was validated.

Unlike the wale direction, the results of the independent sample $t$-test for the course direction did not show a statistically significant difference between the breaking strength of treated $(\mathrm{M}=114.50, \mathrm{SD}=13.14, \mathrm{df}=9)$ and untreated $(\mathrm{M}=114.50, \mathrm{SD}=9.00, \mathrm{df}=9)$ samples; $t(18)=0.00, p>.05$. Therefore, the null hypothesis was accepted (Table 1$)$. The results do not validate the preliminary study of the significant effects of food-grade treatment on the elastic recovery of the ham nets. Therefore, the significant difference in elastic recovery in the course direction between the treated and untreated ham nets stated in the preliminary study was validated.

\subsection{Bursting Strength}

The independent samples $t$-test did not indicate a statistically significant difference between the bursting strength of the treated $(\mathrm{M}=120.64, \mathrm{SD}=3.19, \mathrm{df}=9)$ and untreated $(\mathrm{M}=120.29, \mathrm{SD}=2.48, \mathrm{df}=9)$ samples; $\mathrm{t}(18)=-0.277, p>.05$, Therefore, the null hypothesis was accepted (Table 1). The results indicate the coating treatment does not significantly affect the bursting strength of the treated ham nets.

\subsection{Morphology Analysis Using SEM Images}

The scanning electron microscope (SEM) images of the untreated sample show a normal geomorphological condition with no visible swelling and relapse of the fibers (Figure 4). However, the visual assessment does not identify any breakage or damage of the inner fibers. On the other hand, the SEM images of the treated sample (Figure 5) show food-grade chemicals adhered to the inner fibers with swelled diameters of the fibers due to the absorption of chemicals. The visual assessment identifies the appearance of swelling in addition to viscous surfaces of the fibers. 


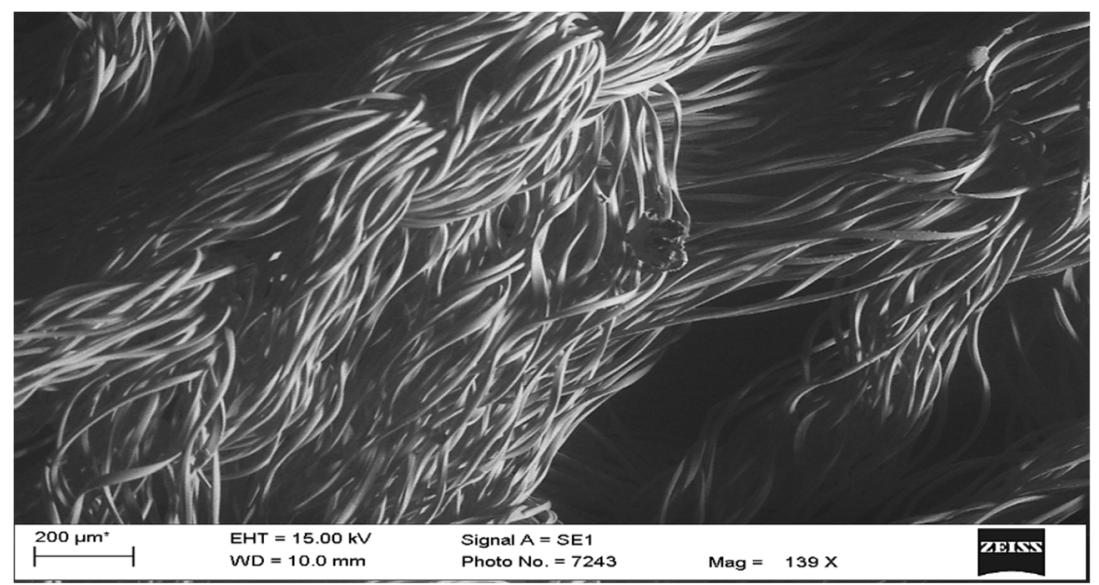

Figure 4. SEM view of untreated ham net fibers.

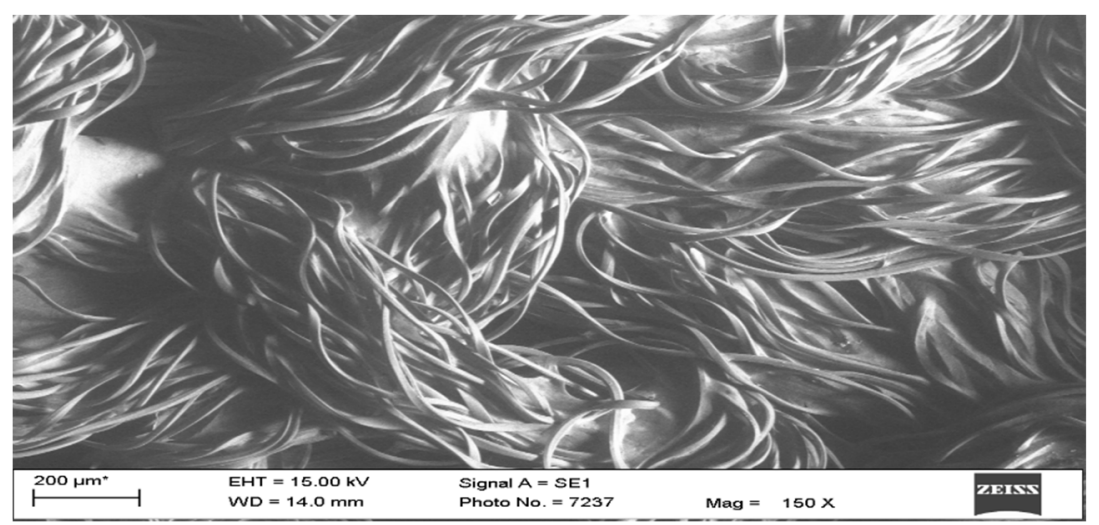

Figure 5. SEM view of treated ham net fibers.

\subsection{Implications}

Breaking strength plays a vital role during the aging of dry-cured ham. The statistical analysis showed no treatment to have a positive effect on the breaking strength of ham nets, which justifies the effectiveness of the treated ham nets for the dry-cured ham industry.

Similarly, being a multidirectional applied force, bursting strength is the major mechanical performance parameter to evaluate in ham nets during aging. The statistical analysis also indicates that the treatment of ham nets with a PG solution does not affect the bursting strength capabilities and could potentially decrease the risk of net failure during the aging process.

The earlier literature supports the use and efficacy of food-grade chemicals in drycured ham aging and the current research indicates no negative implications on the mechanical performance characteristics for treated vs. untreated nets.

\section{Conclusions}

For each of the individual mechanical performance characteristics (abrasion resistance, elastic recovery, breaking strength, and bursting strength), the results indicate the treatment on a circular knit ham net with a food-grade chemical solution of propylene glycol, propylene glycol alginate, and carrageenan has little to no effect on the mechanical performance characteristics of ham nets. For the dry-cured ham producers, this coating treatment on a textile with this solution, as part of an integrated pest management program, will perform just as well as-if not better than - the ham nets that are currently available in the market. Furthermore, this study supports the use of food-grade chemicals and the use of ham nets to increase the end-use functionality and provide ham producers with an option for integrated pest management without compromising in terms of mechanical performance needs. 


\section{Limitations and Future Recommendations}

An additional mechanical performance test, such as a tear test, could have been incorporated to establish the tear strength of the sample ham nets.

The use of ham nets of different fiber contents, such as cotton or a cotton/polyester blend nets, is recommended to investigate the mechanical performance characteristics.

Food-grade PG solution at the polymer extrusion stage can be applied to further investigate the effect of food grade chemical solution on the mechanical performance characteristics of polymer-treated ham nets for a longer time, with a view towards labor saving in the dry-cured ham aging process.

Author Contributions: Conceptualization, C.F.; methodology, M.A.-A.; software, M.A.-A.; validation, C.F., W.S. (Wes Schilling), S.K. and Y.L.C.; formal analysis, M.A.-A.; investigation, C.F. and W.S. (Wes Schilling); resources, C.B., C.F. and S.K.; data curation, M.A.-A., W.S. (Wenjie Shao) and A.V.; writing-original and draft preparation, M.A.-A. and C.F.; writing-reviewing and editing, C.B., W.S. (Wes Schilling) and C.F.; visualization, M.A.-A.; supervision, C.F.; project administration, W.S. (Wes Schilling), C.F., and C.B.; funding acquisition, C.F. and C.B. All authors have read and agreed to the published version of the manuscript.

Funding: This research project was funded by the United States Department of Agriculture (USDA) under the Methyl Bromide transition program, grant number 2017-51102-27270.

Data Availability Statement: Not applicable.

Conflicts of Interest: The authors declare no conflict of interest.

\section{References}

1. Campbell, Y.L.; Zhang, X.; Shao, W.; Williams, J.B.; Kim, T.; Goddard, J.; Abbar, S.; Phillips, T.W.; Schilling, M.W. Use of Nets Treated With Food-Grade Coatings on Dry-Cured Ham to Control Tyrophagus Putrescentiae Infestations without Impacting Sensory Properties. J. Stored Prod. Res. 2018, 76, 30-36. [CrossRef]

2. Campbell, Y.L.; Zhao, Y.; Zhang, X.; Abbar, S.; Phillips, T.W.; Schilling, M.W. Mite Control and Sensory Evaluations of Dry-Cured Hams with Food-Grade Coatings. Meat Muscle Biol. 2017, 1. [CrossRef]

3. Zhang, X.; Campbell, Y.L.; Phillips, T.W.; Abbar, S.; Goddard, J.; Schilling, M.W. Application of food-grade ingredients to nets for dry cured hams to control mite infestations. Meat Muscle Biol. 2017, 1. [CrossRef]

4. Garavaglia, C.; Mariani, P. How Much Do Consumers Value Protected Designation of Origin Certifications? Estimates of Willingness to Pay for PDO Dry-Cured Ham in Italy. Agribusiness 2017, 33, 403-423. [CrossRef]

5. Processed Meat-United States: Statista Market Forecast. Available online: https://www.statista.com/outlook/40020100/109 /ham-bacon/united-states (accessed on 17 August 2021).

6. Swine. Comparison of European \& American Systems of Production and Consumption of Dry-Cured Hams. Available online: https:/ / swine.extension.org/comparison-of-european-american-systems-of-production-and-consumption-of-dry-curedhams / (accessed on 17 August 2021).

7. Jiménez-Colmenero, F.; Ventanas, J.; Toldrá, F. Nutritional Composition of Dry-Cured Ham and Its Role in a Healthy Diet. Meat Sci. 2010, 84, 585-593. [CrossRef] [PubMed]

8. Rentfrow, G. How to Make a Country Ham. Available online: https:/ / uknowledge.uky.edu/cgi/viewcontent.cgi?referer=https: / / scholar.google.com / \&httpsredir=1\&article=1145\&context=anr_reports (accessed on 17 August 2021).

9. Jiang, S.Q.; Newton, E.; Yuen, C.W.M.; Kan, C.W. Chemical Silver Plating on Cotton and Polyester Fabrics and Its Application on Fabric Design. Text. Res. J. 2006, 76, 57-65. [CrossRef]

10. John, M.J.; Anandjiwala, R.D. Surface modification and preparation techniques for textile materials. In Surface Modification of Textiles; Wei, Q., Ed.; Woodhead Publishing: Cambridge, UK, 2009; pp. 1-25.

11. Hall, M.E. Coating of technical textiles. In Handbook of Technical Textiles; Horrocks, A.R., Anand, S.C., Eds.; CRC Press: Boca Raton, FL, USA, 2000; pp. 173-186.

12. Nadi, A.; Boukhriss, A.; Bentis, A.; Jabrane, E.; Gmouh, S. Evolution in the Surface Modification of Textiles: A Review. Text. Prog. 2018, 50, 67-108. [CrossRef]

13. Pei, E.; Shen, J.; Watling, J. Direct 3D Printing of Polymers onto Textiles: Experimental Studies and Applications. Rapid Prototyp. J. 2015, 21, 556-571. [CrossRef]

14. Aznar, M.; Alfaro, P.; Nerin, C.; Kabir, A.; Furton, K.G. Fabric Phase Sorptive Extraction: An Innovative Sample Preparation Approach Applied to the Analysis of Specific Migration from Food Packaging. Anal. Chim. Acta 2016, 936, 97-107. [CrossRef] [PubMed]

15. Hasani, H.; Avinc, O.; Khoddami, A. Effects of different production processing stages on mechanical and surface characteristics of polylactic acid and PET fibre fabrics. Indian J. Fibre Text. Res. (IJFTR) 2017, 42, 31-37. 
16. Niekraszewicz, A.; Lebioda, J.; Hoffman, J.; Ruszkowski, K.; Struszczyk, H. Anti-mite modified polypropylene fibres and bedding inserts containing such fibres. Fibres Text. East. Eur. 2005, 6, 24-27.

17. Rahel, J.; Jonasova, E.; Nesvorna, M.; Klubal, R.; Erban, T.; Hubert, J. The Toxic Effect of Chitosan/Metal-Impregnated Textile to Synanthropic Mites: Chitosan/Metal-Impregnated Textile Kills Mites. Pest Manag. Sci. 2013, 69, 722-726. [CrossRef] [PubMed]

18. Abbar, S.; Amoah, B.; Schilling, M.W.; Phillips, T.W. Efficacy of Selected Food-Safe Compounds to Prevent Infestation of the Ham Mite, Tyrophagus Putrescentiae (Schrank) (Acarina: Acaridae), on Southern Dry-Cured Hams: PreventingTyrophagus Putrescentiaeinfestation of Hams with Food-Safe Compounds. Pest Manag. Sci. 2016, 72, 1604-1612. [CrossRef] [PubMed]

19. Wang, X.; Liu, X.; Deakin, C.H. Physical and mechanical testing of textiles. In Fabric Testing; Hu, J., Ed.; Woodhead Publishing: Cambridge, England, 2008; pp. 90-124.

20. Özdemir, H.; Mert, E. The Effects of Fabric Structural Parameters on the Tensile, Bursting, and Impact Strengths of Cellular Woven Fabrics. J. Text. Inst. 2013, 104, 330-338. [CrossRef]

21. Al-Amin, M.; Shao, W.; Varadarajan, A.; Freeman, C.; Campbell, Y.L.; Schilling, W.M.; Kundu, S.; Black, C. Comparison of the Mechanical Properties between Treated and Untreated Ham Nets. Text. Res. J. 2020, 90, 1237-1244. [CrossRef]

22. D13 Committee. Test Method for Bursting Strength of Textile Fabrics-Diaphragm Bursting Strength Tester Method; ASTM International: West Conshohocken, PA, USA, 2018.

23. D13 Committee. Test Method for Breaking Strength and Elongation of Textile Fabrics (Grab Test); ASTM International: West Conshohocken, PA, USA, 2017.

24. D13 Committee. Test Method for Abrasion Resistance of Textile Fabrics (Martindale Abrasion Tester Method); ASTM International: West Conshohocken, PA, USA, 2016.

25. D13 Committee. Practice for Conditioning and Testing Textiles; ASTM International: West Conshohocken, PA, USA, 2016.

26. Nautiyal, M.; Vasugi, N. Evaluating the performance attributes of single jersey conventional and organic cotton. Int. J. Home Sci. 2018, 4, 202-207.

27. Wardiningsih, W.; Troynikov, O.; Molotnikov, A.; Estrin, Y. Influence of Protective Pad Integrated into Sport Compression Garments on Their Pressure Delivery to Athlete's Lower Limbs. Procedia Eng. 2013, 60, 170-175. [CrossRef]

28. Ross, A.; Willson, V.L. Basic and Advanced Statistical Tests: Writing Results Sections and Creating Tables and Figures; Sense Publishers: Rotterdam, The Netherlands, 2017.

29. De Winter, J.C. Using the Student's t-test with extremely small sample sizes. Pract. Assess. Res. Eval. 2013, 18, 10.

30. Uzun, M.; Patel, I. Tribological properties of auxetic and conventional polypropylene weft knitted fabrics. Arch. Mater. Sci. Eng. 2010, 44, 120-125.

31. Jinyun, Z.; Yi, L.; Lam, J.; Xuyong, C. The Poisson ratio and modulus of elastic knitted fabrics. Text. Res. J. 2010, 80, 1965-1969. [CrossRef] 